\title{
Social Growth Problems Experienced by First-Grade Students at Bseera District, Jordan
}

\author{
Atif Eid Alrfooh ${ }^{1}$ \\ ${ }^{1}$ Department of Special Education, Al-Hussein Bin Talal University, Ma'an, Jordan \\ Correspondence: Atif Eid Alrfooh, Department of Special Education, Al-Hussein Bin Talal University, Ma'an, \\ Jordan. E-mail: dr_atifr@yahoo.com
}

Received: December 27, 2013

Accepted: February 25, 2014 Online Published: March 26, 2014

doi:10.5539/ies.v7n4p69

URL: http://dx.doi.org/10.5539/ies.v7n4p69

\begin{abstract}
This study aims at exploring the problems of social growth experienced by students, and as recognized by teachers at "Bseera", Jordan. The study sample consisted of (88) male and female students from first-grade in the public schools in Bseera/governorate of Tafila/Jordan 2009/2010. The researcher has developed a questionnaire which consists of (23) paragraphs, while four-graded standard has been chosen to questions related to social problems. The results showed that the most important problems experienced by students are (need of help to do something) then (encroach upon the property of his colleagues) and then (have no relationships with adults) and (does not care about the completion of the required work). The results also showed that there were statistically significant differences due to the school where the student is being taught, and there were statistically significant differences between males and females in favor of females. The study did not show any statistically significant differences due to variables of the mothers and fathers educational level.
\end{abstract}

Keywords: psychological adjustment, elementary school, father's educational level, behavioral problems, growth

\section{Introduction}

The school is considered the second social institution after home in terms of its impact on child rising and care. The school importance arises from the educational process that refreshes the minds of children. The normal function of school is to receive children at an early age (about 5 years and 8 months) which is the first step to deal with them immediately after the role of their families, placing them in an educational strategic position with a complete supervision to enable students to explore the positive and negative trends in their personalities.

Perhaps one of the most negative, complex and problematic aspects of school life is the behavioral problems practiced by some children in the school.

Sometimes children may assault a colleague believing that he cannot respond to abuse or because the of weakness and inability to face them independently or due to the parents method of education which may kill the natural spirit of aggression of their child in a severe and dangerous way, The child also may be shy and quiet dealing with stubborn aggressive colleges resulting in the child's dislike of school and feeling of alienation. If the child has not received good educational treatment in school and has understood the developed curriculum, the educational attainment would be going backward, also the boredom and stress will cover his life and consequently, the child will create aggressive relationships either with peers or with teachers, in addition to dark image of human life, especially after frequent frustrations.

The system of children's daily lives changes decisively when they begin the school life.

Learning process provides the child with a sense of competition and power, which helps in increasing the aggressive trends and spread them to others as well as to the assets of the school.

The teacher remains a key element in the discovery of behavior changes of children and identifies many forms of disorder that hurt children in the classroom, and thus the burden of identifying such children, and diagnosing their problems, and helping them to adapt with the social life at school lies on the shoulders of the teacher. The teacher role is to help students to grow physically, mentally and emotionally so that to achieve the educational goals and to develop the good behaviors through the encouragement and guidance in addition to investing their powers to the greatest extent and to help them keep emotional balance and develop found trends. 
First grade students suffer from (lack of social adjustment), and teachers have difficulties controlling them, and attracting them to the social atmosphere of school. At the beginning of the school, students sometimes keep crying for more than week and become unable to adapt to colleagues and teachers in the classroom. Additionally, such students are introverted, unsocial, do not have companions in the classroom and suffer from changes of mood. The reason behind this is the strong relationship with parents, and mothers over care of their children, as they do not allow them to play or engage with other children or act independently. Moreover, mothers prevent their children from joining cultural or entertainment club in addition to many other reasons (osrty.com).

It is necessary to define the term adaptation: In language adaptation refers to harmony and convergence; it is the opposite of repulsion, clash or collision (Botros, 2008). Idiomatically, there are several definitions:

(1) Definition of Fahmi (1987) as indicated by Botros (2008) in his book: the ongoing dynamic process that is designed by the person to change the behavior to create a more compatible relationship between the individual and his/her environment.

(2) Definition of Al-Rifai (1987) as indicated by Botros (2008) a set of responses and reactions in which an individual modifies the behavior to form a composition of the psychological, social and natural environment.

(3) Al-Hashemi (1986) defined adaptation in psychological studies as: the interactive and continuous (dynamic) process practiced by humans consciously or subconsciously, which aims to change behavior to become more compatible with the motives and requirements of his / her environment.

Adjustment is divided into two types: psychological adjustment and social adjustment. Psychological adjustment indicates that most human behavior is self-attempts to achieve compatibility with the environment, either on a personal level or on a social level. The concept of compatibility indicates the existence of harmonious relationships with the environment including the ability to satisfy the most biological and social human needs and meet most demands. In addition, compatibility includes all data and changes in behavior which are necessary to meet the satisfaction level in the context of a harmonious relationship with the environment (Botros, 2008).

Most researchers agree on the importance of integration between psychological health and good compatibility, where they see that the study of psychological health is a study of the compatibility, and that cases of non-compliance are only signs of impaired mental health, but one of its manifestations.

Ghaith (2006) have shown that the concept of psychological adaptation is one of the most important factors in psychological balance and psychological health. People usually are exposed to pressures as well as internal and external conflicts, and they have to face the contrasting desires and personal motivations in order to keep the continuity of psychological balance. Some researchers believe that psychological health is the expression of adaptation, and adjustment is an evidence for psychological health, if the adaptation is worse than mental health comes worse, and if the adaptation has improved then mental health would improve.

With regard to the other type of adaptation and the social adjustment (Botros, 2008) has noted that social adjustment means the way to enable the individual to be socially and psychologically integrated, any attempt that helps individual to achieve self and social development in the right and proper way and to create constructive social trends.

Ghaith (2006) has defined social adjustment as the process which involves making changes in the person or the environment, or both in order to achieve harmony in the relationship between them.

The most important aspects of social development at this stage could be summarized as follows:

1) At this stage, social normalization that leads to the formation of behavioral standards occurs.

2) Students tend to participate in personal communication and in peer activities.

3) Students tend to pay attention and care for looking and style.

4) Student tends to have social independence and particularly within the family.

5) Keep pace within the group and the desire for self-assertion.

6) Look for a model and a pattern.

7) Increase of the ability to understand and discuss social issues.

8) Sensitivity to criticism and the tendency to debate with adults.

\section{Importance of the Study}

The importance of this study emerges from the importance of the subject, which is the social growth problems among the first primary grade students as recognized by their teachers. 
Elementary stage of the child's life is an important one and psychologists consider it as the basic stage in the formation of the child's personality in the future.

\section{Problem Statement}

Most of the first grade teachers have complaints from the behaviors practiced by those students, particularly in social aspects, which hinders teaching and learning process both inside and outside the classroom in extracurricular classes and thus it is reflected on students' academic achievement. The information and skills received by the first grade students are essential and fundamental in which all future information, knowledge and skills in the next grades will be based on. In order to keep on the fine quality of student learning in the future, we have to create appropriate conditions for learning in the first grade and detect all obstructions and maybe, social problems are the most prominent problems that can lead to hinder children's' learning process, hence these problems must be taken into consideration and the extent of popularity among children should be identified in order to facilitate treatment in the future, bringing students to the appropriate level of social growth which in turn facilitates teaching and learning process in this grade and the following stages, and this drives the researcher to face and discuss this problem.

\section{Aim of the Study}

This study aims at exploring social growth problems experienced by the first primary grade students as recognized by their teachers in the Bseera district. Specifically, the study seeks to answer the following question and examine the following assumptions: Question: What are the social growth problems experienced by the first primary grade students as recognized by the teacher in Bseera district.

\section{Hypotheses}

1) There are no statistically significant differences at $(\alpha \leq 0.05)$ in the problems of social development among the first primary grade students attributed to the school.

2) There are no statistically significant differences at $(\alpha \leq 0.05)$ in the problems of social development among the first primary grade students attributed to the gender (male, female).

$3)$ There are no statistically significant differences at $(\alpha \leq 0.05)$ in the problems of social development among the first primary grade students due to the mother level of education.

4) There are no statistically significant differences at $(\alpha \leq 0.05)$ in the problems of social development among the first primary grade students due to the father's level of education.

\section{Previous Studies}

Al-Bkor (1985) identifies the prevailing classroom forms of aggression among primary stage students and the impact of gender, age and size of class. To achieve this purpose, a sample of 500 school sections has been selected and teachers have to answer questions of the measuring instrument developed by the researcher. The study results showed that in general, there is a similarity in the common types of aggression at the primary stage. The most common types of aggression are: snitching, beatings with hands, swearing, pushing and threats. The study also showed that males are more aggressive than females, and that the students of lower primary schools (LP schools) are more aggressive than higher primary schools (HP schools). In addition, students at large-size class show more aggressive behaviors than small and medium-sized classes, and small size classes are more aggressive than the medium size.

Bader (1989) aimed at identifying the forms of aggressive behavior of primary school children in the classroom. For this purpose, the sample consisted of 270 divided equally between males and females. The study found that the most prevalent forms of aggressive behavior are: slanders, lies, insults, and not following the hygienic rules, while the least common behavior is imitating the teacher, the use of impolite and obscenities words and the lack of obedience.

Also, it was found that males are more aggressive than females.

The aim of a study conducted by Baybars (1988) was to identify the common concerns of pre-school children in Jordan, which was influenced by gender and age. The sample consisted of 122 male children and 123 female children. It was found that the most common concerns among children are: fear of the unseen, fear of animals, fear of natural phenomena. There were no significant differences due to gender on these concerns but there are some concerns which have noticed in males such as fear of mutilated and deformed shapes, car accidents, wounds, while female's fears were such as walking alone and staying alone.

In a study conducted by Capes (1990) aiming to know the effect of child's stick to the beliefs of parents on the 
social adjustment of the first primary grade students. The sample consisted of children from 150 families, and the study indicated the impact of the first primary grade child sickness to his parents beliefs, which is reflected on social adaptation.

Davis (1993) study aimed to know the effect of parental control on the social adjustment of children in first grade students through teacher's observations. The sample included 150 children from the first primary grade. The study revealed differences in the impact of parental control over the females more than its impact on the males. Also, it was found that the first grade children in private schools are more adaptable than the first primary grade children in public schools in general.

Hijazi (1988) has studied mother's methods of dealing with aggressive behavior patterns to their children at the age of five, through a series of questions prepared by the researcher and presented to 100 mothers. It was found that the most used methods of controlling the aggressive behavior patterns are beating and rebuke, and that mother also encourages this behavior outside home. Methods of dealing with aggressive patterns of behavior are affected by mother's level of education, the mother of higher educational level tends to use advice and guidance more than beatings and rebuke.

The study of Kidweell (1988) aimed to know the effect of family involvement on the social adjustment of first primary grade children using the sample of 113 children. It was found that there are significant differences between families in which raising up children is the responsibility of mothers and families in which servants are responsible for raising up children regarding the social adjustment of first primary grade children and in favor of families of mothers.

The study also showed the importance of the family involvement on the child's social adjustment.

The aim of Lorenz (1990) study is to identify the difference between the socially isolated child and the socially acceptable child in the concept of friendship, the ability to solve social problems, social adjustment, and self-perception of unity and isolation. The sample included 200 children at the elementary stage. It was found that socially isolated children show less development of the concept of friendship, less ability to cope with social problems, poor social adjustment in addition to the increased feelings of loneliness and isolation.

The aim of Moynihan (1989) study is similar to kidweell (1988) study, and the purpose of this study was to investigate the relationship between family construction and social adjustment for the first primary grade children from the perspective of teachers. The selected sample consists of 37 children in the first primary grade. The study revealed a significant relationship between child's social adjustment and the length of time spent with the family.

The study also showed that the male children show poor social adjustment in disconnected or broken families, more than females in these families.

The aim of a study conducted by Whitaker (1993) was to identify the effect of maternal tenderness, deprivation and emotional suppression on shyness behavior in the first primary grade students. The study sample consisted of mothers and teachers of the first primary grade children. The study showed a relationship between mothers low level of passion and the increase of the behavior of shyness from the perspective of teachers of the first primary grade children. Additionally, sudden change in the emotional behavior of the parents increases the behavior shyness in the first primary grade children from the perspective of mothers. Also, it was found that mothers with a high level of education are more aware of the behavior of shyness in children than less educational level mothers.

From the review of studies discussing one of the emotional or social aspects in children, the following points are clarified:

a. Children face some emotional and social problems such as slanders, insults, lies, loneliness, social isolation, fear and shyness.

b. The male children are more aggressive than females.

c. Boys show poor social adjustment in broken families, more than females in these families.

d. Mother's level of education affects both the aggressive behavior and the behavior of a child's shyness.

\section{Methods and Procedures}

\subsection{Study Population}

The study population consists of all first primary grade students in the schools of Ministry of Education in the District of Bseera/Tafila for the academic year 2009/2010. The number is (572) male and female students who 
are distributed according to schools and sections.

\subsection{Sample of the Study}

The study sample consisted of (88) male and female students from first grade primary schools at the Ministry of Education in the District of Bseera / Tafila for the academic year 2009/2010, representing (16\%) of the total community.

\subsection{Study Instrument}

A questionnaire developed to explore the social problems experienced by students of the first primary grade, by referring to the educational literature on this subject and to benefit from previous studies. The researcher has formulated the items of, which consists of (23) items. A four-graded scale was used for the social problems questions as follows:

a) Always true (4), b) Often true (3), c) Rarely true (2), and d) True/I do not know.

The questionnaire consist of two parts, the first included preliminary data concerning the student as follows: Name of school, gender, section, the educational level of father, the educational level of mother. The second part included the items that reflect the problems of social development experienced by first primary grade students.

\subsection{Reliability of the Questionnaire}

With regard to reliability of the questionnaire, testing and retesting method has been used to verify the reliability of the instrument. The tests were applied to a sample of the study population (20) individuals, where correlation coefficient was 0.89 in the pre and post tests for the option (always true), and 0.86 correlation coefficient for the option (often true), and 0.92 for the option (rarely true) and .91 for the option (true/I do not know). These coefficients are appropriate to consider the instrument appropriate and valid.

\subsection{Methods}

The researcher distributed the questionnaire on teachers of first grade primary school included in the sample by hand. The aims of the study and how to fill the questionnaire for each student were explained to them, and after filling the questionnaire by the teachers, questionnaires were collected and checked, then entered into a computer in preparation for the analysis of the results using the method of the statistical program SPSS.

\subsubsection{Statistical Methods}

To answer the questions of the study, frequency, means and standard deviations have been extracted using the analysis of variance and a posteriori comparisons test to find out the differences.

\section{Discussion}

With respect to answering the study question, which states (What are the problems of social development experienced by students of the first primary grade, as recognized by the teacher in Bseera) frequencies and percentages for each of the group items contained in the questionnaire have been found. Table 1 shows these results.

It's obvious from table 3 that the problem (need help to do something) came in the first place among the social problems experienced by first primary grade students, as recognized by the teacher Bseera, and this problem got a percentage of $(6.54 \%$ ), while the items (acquires the property of his colleagues constantly) and (do not have relationships with adults) was in the second rank with a percentage of (5.60\%). In the third place, the problem (not interested in the completion of the required work) gained a percentage (4.98\%) With regard to the first hypothesis, which states (There are no statistically significant differences $(\alpha=0.05)$ in the problems of social development among the first primary grade students $\mathrm{s}$ attributed to the school), the arithmetic mean and standard deviation of the study sample were found. Table 2 reveals the results.

It is clear from Table 2 that there are apparent differences between the means in the questionnaire of social development problems according to the school. To explore whether these differences are statistically significant, the researcher used analysis of variance to find out the effect of the school variable, as shown in Table 3.

It is noticed from Table 3 that there are statistically significant differences in the problems of social development among first primary grade students attributed to the school where the student is being taught. To explore these differences, Scheffe test was used to make posteriori comparisons between the means as shown in Table 4. 
Table 1. Frequencies and percentages and the relative importance (rank) problems of social development experienced by students of the first primary grade, as recognized by the teacher in Bseera

\begin{tabular}{lllll}
\hline No. & Statement & Frequency & Percentage & Rank \\
\hline 1 & Needs help to do something & 324 & 6.54 & 1 \\
2 & possess the property of his colleagues constantly & 281 & 5.60 & 2 \\
3 & Do not have relationships with adults & 281 & 5.60 & 2 \\
4 & Not interested in the completion of the required work & 247 & 4.98 & 3 \\
5 & Refuses to respond to the adults during the speech & 246 & 4.96 & 4 \\
6 & Constantly insists on his position & 235 & 4.74 & 5 \\
7 & Has a tendency to attack his colleagues & 228 & 4.60 & 6 \\
8 & Has a tendency to attack his colleagues (abuse) & 225 & 4.54 & 7 \\
9 & Refusing to share his food & 225 & 4.54 & 7 \\
10 & Not happy when given a leadership role & 225 & 4.54 & 7 \\
11 & Breaks the teacher's rules & 220 & 4.44 & 8 \\
12 & Introvert and withdrawn in the presence of adults & 216 & 4.36 & 9 \\
13 & Works only by urging and encouragement & 216 & 4.36 & 9 \\
14 & Does not have other children who love him & 212 & 4.28 & 10 \\
15 & Not interested in arranging clothes constantly & 210 & 4.24 & 11 \\
16 & Mock at teacher's instruction & 207 & 4.18 & 12 \\
17 & Does not play with children or participate in activities & 184 & 3.71 & 13 \\
18 & Assault on others food and spoil it & 179 & 3.61 & 14 \\
19 & Face any position and withdraw from positions quickly & 163 & 3.29 & 15 \\
20 & Assault on the food of others and eat from it & 161 & 3.25 & 16 \\
21 & Does not depend on himself in eating & 157 & 3.17 & 17 \\
22 & Does not go outside during the rest of the class & 156 & 3.15 & 18 \\
23 & Hates school and not interested in it & 154 & 3.10 & 19 \\
\hline
\end{tabular}

Table 2. Arithmetic means and standard deviations for a study sample questionnaire to the problems of social growth by school

\begin{tabular}{|c|c|c|c|c|}
\hline No. & School & $\begin{array}{l}\text { Number } \\
\text { Students }\end{array}$ & $\begin{array}{l}\text { Arithmetic } \\
\text { Mean }\end{array}$ & $\begin{array}{l}\text { Standard } \\
\text { Deviation }\end{array}$ \\
\hline 1 & Bosra primary coeducation school & 19 & 5.45 & 0.60 \\
\hline 2 & Nusaiba Almazenya primary school & 24 & 6.10 & 0.85 \\
\hline 3 & Grandal primary coeducation school & 17 & 4.67 & 0.81 \\
\hline 4 & Ain Jalout primary school & 8 & 5.15 & 0.90 \\
\hline 5 & Bseera primary school & 20 & 6.04 & 0.53 \\
\hline Total & & 88 & 5.58 & 0.90 \\
\hline
\end{tabular}


Table 3. The analysis of variance results to determine the statistical significance of the differences between schools means

\begin{tabular}{lllllll}
\hline $\begin{array}{l}\text { Source of variance } \\
\text { (school) }\end{array}$ & $\begin{array}{l}\text { Sum of the } \\
\text { squares }\end{array}$ & $\begin{array}{l}\text { Degrees } \\
\text { freedom }\end{array}$ & $\begin{array}{l}\text { Mean } \\
\text { squares }\end{array}$ & of & (F)Value & $\begin{array}{l}\text { Significance } \\
\text { level }\end{array}$ \\
\hline Between the groups & 26.68 & 4 & 6.67 & 12.26 & 0.00 \\
Within groups & 45.12 & 83 & 0.544 & & \\
\hline Total & 71.81 & 87 & & & \\
\hline
\end{tabular}

Table 4. Results of Scheffe's test of posteriori comparisons between the means of the social development problems in the first primary grade students attributed to the school

\begin{tabular}{|c|c|c|c|c|c|}
\hline School & $\begin{array}{c}\text { Bosra } \\
\text { primary } \\
\text { school }\end{array}$ & $\begin{array}{l}\text { Nusaiba } \\
\text { Almazenya }\end{array}$ & $\begin{array}{c}\text { Grandal } \\
\text { primary } \\
\text { school }\end{array}$ & $\begin{array}{c}\text { Ain } \\
\text { Jalout }\end{array}$ & $\begin{array}{c}\text { Bseera } \\
\text { primary } \\
\text { school }\end{array}$ \\
\hline Bosra primary & & $*(0.03)$ & $*(0.01)$ & 0.86 & 0.09 \\
\hline Nusaiba Almazenya & & & $*(0.00)$ & $*(0.01)$ & 0.99 \\
\hline Grandal primary school & & & & 0.56 & $*(0.00)$ \\
\hline Ain Jalout & & & & & $*(0.03)$ \\
\hline Bseera primary school & & & & & \\
\hline
\end{tabular}

Table 5. Arithmetic means and standard deviations for a study sample questionnaire on the problems of social growth distributed according to gender (male, female)

\begin{tabular}{lllll}
\hline No. & Gender & Number of Students & Arithmetic mean & Standard deviation \\
\hline 1 & Male & 44 & 5.05 & 0.74 \\
2 & Female & 44 & 6.12 & 0.73 \\
\hline Total & & 88 & 5.58 & 0.90 \\
\hline
\end{tabular}

With regard to the second hypothesis, which provides, "there are no statistically significant differences $(\alpha \leq 0.05)$ in the problems of social development among the first primary grade students attributed to the gender (male, female), the mean and standard deviation of the study sample are shown". Table 5 represents the results.

It is clear from Table 5 that there are apparent differences in the means between males and females in the questionnaire of social development problems. To explore whether these differences are statistically significant, analysis of variance was used to find out the impact of the gender variable, as shown in table 6 .

It is obvious from table 6 that there are statistically significant differences in the problems of social development among first primary grade students attributed to the gender. By reference to the means in table 4, it is found that the mean of females is higher than the mean of males, and thus, these differences are in favor of females.

With regard to third hypothesis, which states "There are no statistically significant differences at $(\alpha \leq 0.05)$ in the problems of social development among the first primary grade students due to the mother level of education".

Table 6. The results of analysis of variance to determine statistical significance differences between means of the gender

\begin{tabular}{lccccc}
\hline $\begin{array}{l}\text { Source of variance } \\
\text { (school) }\end{array}$ & $\begin{array}{c}\text { Sum of the } \\
\text { squares }\end{array}$ & $\begin{array}{c}\text { Degrees of } \\
\text { freedom }\end{array}$ & $\begin{array}{c}\text { Mean of } \\
\text { squares }\end{array}$ & (F)Value & $\begin{array}{c}\text { Significance } \\
\text { level }\end{array}$ \\
\hline Between the groups & 24.88 & 1 & 24.88 & 45.62 & 0.00 \\
Within groups & 46.92 & 86 & 0.546 & & \\
Total & 71.80 & 87 & & & \\
\hline
\end{tabular}


Table 7. Arithmetic means and standard deviations for the study sample questionnaire of social growth problems distributed according to mother's level of education

\begin{tabular}{|c|c|c|c|c|}
\hline No. & Educational level & $\begin{array}{l}\text { Number of } \\
\text { Students }\end{array}$ & $\begin{array}{l}\text { Arithmetic } \\
\text { Mean }\end{array}$ & $\begin{array}{l}\text { Standard } \\
\text { Deviation }\end{array}$ \\
\hline 1 & Illiteracy & 6 & 5.23 & 0.65 \\
\hline 2 & Primary & 36 & 5.67 & 1.01 \\
\hline 3 & Secondary & 28 & 5.71 & 0.90 \\
\hline 4 & Diploma & 10 & 5.69 & 0.66 \\
\hline 5 & Bachelor & 5 & 4.84 & 0.72 \\
\hline 6 & High Diploma & 3 & 5.03 & 0.15 \\
\hline Total & & 88 & 5.58 & 0.90 \\
\hline
\end{tabular}

The mean and standard deviation of the study sample were extracted. Table 7 shows the results. It is clear from Table 7 that there are apparent differences between the means for variable of mother's level of education in the questionnaire of social development problems.

To explore whether these differences are statistically significant, analysis of variance was used to extract the effect of the level of mother's education variable, as shown in Table 8.

Table 8 . The results of analysis of variance to identify the statistical significance of the differences of means of the impact of mother's level of education

\begin{tabular}{lccccc}
\hline $\begin{array}{l}\text { Source of variance } \\
\text { (school) }\end{array}$ & $\begin{array}{c}\text { Sum of the } \\
\text { squares }\end{array}$ & $\begin{array}{c}\text { Degrees of } \\
\text { freedom }\end{array}$ & $\begin{array}{c}\text { Mean of } \\
\text { squares }\end{array}$ & (F)Value & $\begin{array}{c}\text { Significance } \\
\text { level }\end{array}$ \\
\hline Between the groups & 5.82 & 5 & 1.05 & 1.30 & 0.271 \\
Within groups & 66.52 & 82 & 0.81 & & \\
\hline Total & 71.80 & 87 & & & \\
\hline
\end{tabular}

Table 8 illustrates that there are no statistically significant differences in the problems of social development among first primary grade students due to the impact of the variable (level of mothers education, where the value of $(F)=1.30$, significance level $=0.271$ which is not a significant at the significance level $(\alpha \leq 0.05)$.

With regard to the fourth hypothesis, which states (There are no statistically significant differences at $(\alpha \leq 0.05)$ in the problems of social development among the first primary grade students due to the father level of education).

Table 9. Arithmetic means and standard deviations for the study sample questionnaire of social growth problems distributed according to father's level of education

\begin{tabular}{llccc}
\hline No. & Educational level & $\begin{array}{c}\text { Number of } \\
\text { Students }\end{array}$ & $\begin{array}{c}\text { Arithmetic } \\
\text { Mean }\end{array}$ & $\begin{array}{c}\text { Standard } \\
\text { Deviation }\end{array}$ \\
\hline 1 & Illiteracy & 7 & 5.55 & 0.82 \\
2 & Primary & 38 & 5.77 & 0.79 \\
3 & Secondary & 18 & 5.58 & 1.12 \\
4 & Diploma & 7 & 5.17 & 1.10 \\
5 & Bachelor & 6 & 4.83 & 0.63 \\
6 & High Diploma & 1 & 6.00 & 0.88 \\
7 & Master & 1 & 6.20 & 0.96 \\
\hline Total & & 88 & 5.58 & 0.90 \\
\hline
\end{tabular}


The mean and standard deviation of the study sample were extracted as shown in Table 9. It is clear from Table 9 that there are apparent differences between the means of father's level of education variable in the questionnaire of social development problems. To explore whether these differences are statistically significant, analysis of variance was used to find out the effect of the level of father's education variable, as shown in Table 10 .

Table 10. The results of analysis of variance to determine statistical significance of the differences between means of the impact of variable level of father education

\begin{tabular}{lccccc}
\hline $\begin{array}{l}\text { Source of variance } \\
\text { (school) }\end{array}$ & $\begin{array}{c}\text { Sum of the } \\
\text { squares }\end{array}$ & $\begin{array}{c}\text { Degrees of } \\
\text { freedom }\end{array}$ & $\begin{array}{c}\text { Mean of } \\
\text { squares }\end{array}$ & (F)Value & $\begin{array}{c}\text { Significance } \\
\text { level }\end{array}$ \\
\hline Between the groups & 6.50 & 6 & 1.08 & 1.345 & 0.247 \\
Within groups & 65.30 & 81 & 0.80 & & \\
\hline Total & 71.80 & 87 & & & \\
\hline
\end{tabular}

Table 10 illustrates that there are no statistically significant differences in the problems of social development among first primary grade students due to the impact of the variable of father's education level, where the value of $(F)=1.345$, and the significance level $=0.247$ which is not significant at the significance level $(\alpha \leq 0.05)$.

\section{Results and Discussion}

The results showed that the problem which came in the first rank is (need of help to do something). Also, the results of this study were partly different from the results of Al-Bkor (1985) and Bader (1989) studies which showed that the most common aggressive behaviors are snitching, beatings with hands, cursing, threats, and breaking the rules. This can be explained through the different periods in which the study was conducted Al-Bkor (1985) and Bader (1989) while the present study was conducted in the academic year 2009/2010. There is no doubt that there are enormous cognitive development in the current era in which means of modern technology such as computers and the Internet are available and used by the child which can affect the behaviors and acts, and may change and become better.

This result can be interpreted as the outside world for a child is something unknown and therefore he/she needs a continuous assistance by others, especially models such as parents and teachers to discover this world, the reason can also be attributed to the fact that child's ability in the first primary grade to distinguish between the right and wrong things is weak, so that the child needs help to know the right things to follow, practice and stay away from the wrong things.

The problem, which ranked secondly, includes two items (encroaching on private property of his colleagues constantly) and (do not have relationships with adults). With regard to the first item (encroaching on private property of his colleagues constantly), this result matches partly with the results of studies of Hijazi (1988) and Lorenz (1990) where the results of Hijazi (1988) study revealed that the mother's lenient in the case of aggression between the brothers, and encourages aggression outside the house. The study of Lorenz (1990) has indicated that socially isolated children show less development of the friendship concept, less ability to cope with social problems, poor social adjustment in addition to the increased feelings of loneliness and isolation.

Probably, the reason refers to the fact that the child in this grade has a sever love of (ego), therefore seek to take and possess others' things he/she likes, this may be due to the love of domination and control found in children to everything they see and like.

With regard to the second item (do not have relationships with adults), this may be due to a children sense of weakness to the older surrounding people who deal with them, believing that those adults are trying to control them completely either in behaviors, practices or expressions. Perhaps, the reason refers to children's fear form making relationships with adults or from the punishment if they commit a mistake in their behavior towards old people and thus trying to keep away from adults.

In the third place, the problem (not interested in the completion of the required work) the researcher did not find studies focused on this aspect. This result can be explained that the student's ability to focus on the work is weak, so the child's movement may be a lot during the performance of a certain work which leads to lack of focus in the performance of the required work. Possibly, the reason is due to the child disability to sit down for a long time in one place and this hinders the performance of any required work. 
In respect of the first hypothesis, which states?

There are no statistically significant differences at $(\alpha \leq 0.05)$ in the problems of social development among the first primary grade students attributed to the school where the student is being taught.

The results indicated that there are significant differences in social development problems among students of the first primary grade attributed to the school where the student is being taught. Nusaiba Al-Mazenia School showed more problems, then Bseera primary school then Bosra primary school. The results of this study matches partly with results of a study (Al-Bkor, 1985), which indicated that large size classes students are more aggressive than the small size class students which can be explained by looking at the size of the classroom and by student's residence With regard to the second hypothesis, which states?

There are no statistically significant differences at $(\alpha \leq 0.05)$ in the problems of social development among the first primary grade students attributed to the gender (male; female).

Problems in females were higher than in males which can be explained depending on the nature of society and the study sample as it is rural areas which have certain privacy in the raising and preservation of females.

With regard to the third hypothesis, which states?

There are no statistically significant differences at $(\alpha \leq 0.05)$ in the problems of social development among the first primary grade students due to the mother level of education.

The results showed no statistically significant differences at $(\alpha \leq 0.05)$ in the problems of social development among the first primary grade students due to the mother level of education.

The result contradicts with (Whitaker, 1993) which showed a relationship between mothers low level of passion and the increase of the behavior of shyness from the perspective of teachers of the first primary grade children. Additionally, sudden change and fluctuation in the emotional behavior of the parents increases the behavior shyness in the first primary grade children from the perspective of mothers. Also, It was found that mothers with a high level of education are more aware of the behavior of shyness in children than less educational level of mothers.

The difference between the two results can be explained based on the difference between the environments in which the two studies were conducted, as (Whitaker, 1993) was conducted in the western society which is different from the Arab societies.

With regard to the fourth hypothesis, which states?

There are no statistically significant differences at $(\alpha \leq 0.05)$ in the problems of social development among the first primary grade students due to the father level of education. The results showed no statistically significant differences at $(\alpha \leq 0.05)$ in the problems of social development among the first primary grade students attributed to father's level of education.

No previous studies examined the effect of this variable were found, and the result can be explained by the father spending most of his time to work outside home and has no time to follow up the son thoroughly.

In light of the study results, the researcher recommends with the following: The necessity of providing more care in dealing with first primary grade students and guide them to avoid aggression towards their colleagues, whether insults or beatings and to identify the students who made such behaviors and holding a special class for them in the attendance of social advisor at the school to indicate that these behaviors are wrong and must be avoided in addition to providing awards and material and moral incentives for those who quit these behaviors.

In addition, promoting the spirit of cooperation, intimacy and affection between each of the students to share the other in food and drink and implementation the guide class, and encourage entrepreneurship among students to be involved in daily behaviors in order to make the student get rid of the of social development problems which they have and to involve parents in work to rid their children of these problems within the home, in order to reach to integrated growth of the child from all areas.

\section{References}

Al-Bkor, N. (1985). Identifying types of aggression in the elementary classroom (Unpublished Master thesis, University of Jordan, Amman, Jordan).

Baybars, H. S. (1988). Common fears of pre-school children (Unpublished MA thesis, Yarmouk University, Irbid, Jordan).

Botros, B. (2008). The Psychological Health of the Child. Amman, Jordan: Dar Almasera for publication and 
distribution.

Capes, L. R. (1990). Parental Denominational Affiliation and the Social Adaptational Status of First Grade Children (Parents Religion). Abstracts International-B, 53(10), 5481.

Davis, K. D. S. (1993). Maternal Locus-of-Control and the Social Adaptational Status of First Grade Children in an Oregon School. Abstracts International-A, 54(01), 83.

Ghaith, S. (2006). The Psychological Health of children. Amman, Jordan: Dar Safa for publication and distribution.

Hijazi, N. (1988). Mothers methods of dealing with aggressive behavior patterns of their children in the age of five (Unpublished MA thesis, Yarmouk University, Irbid, Jordan).

Kidwell, L. B. (1988). Family Structure and the School Adaptational Status of First Grade Children. Abstracts International-B, 49(11), 5063.

Lorenz, S. (1990). Children without Friends, Dimensions of their Social Reasoning, Self-Perception, and School Adjustment. Abstracts International-A, 52(03), 852.

Moynihan, W. S. (1989). Family Structure and the School Adaptational Status of First Grade Children in an Oregon Public School System in 1987. Abstracts International-B, 50(02), 767.

Whitaker, D. L. (1993). Shyness in First Grade Children and its Relation to Maternal Emotions and restrictiveness. Abstracts International-B, 56(06), 3367.

\section{Copyrights}

Copyright for this article is retained by the author(s), with first publication rights granted to the journal.

This is an open-access article distributed under the terms and conditions of the Creative Commons Attribution license (http://creativecommons.org/licenses/by/3.0/). 